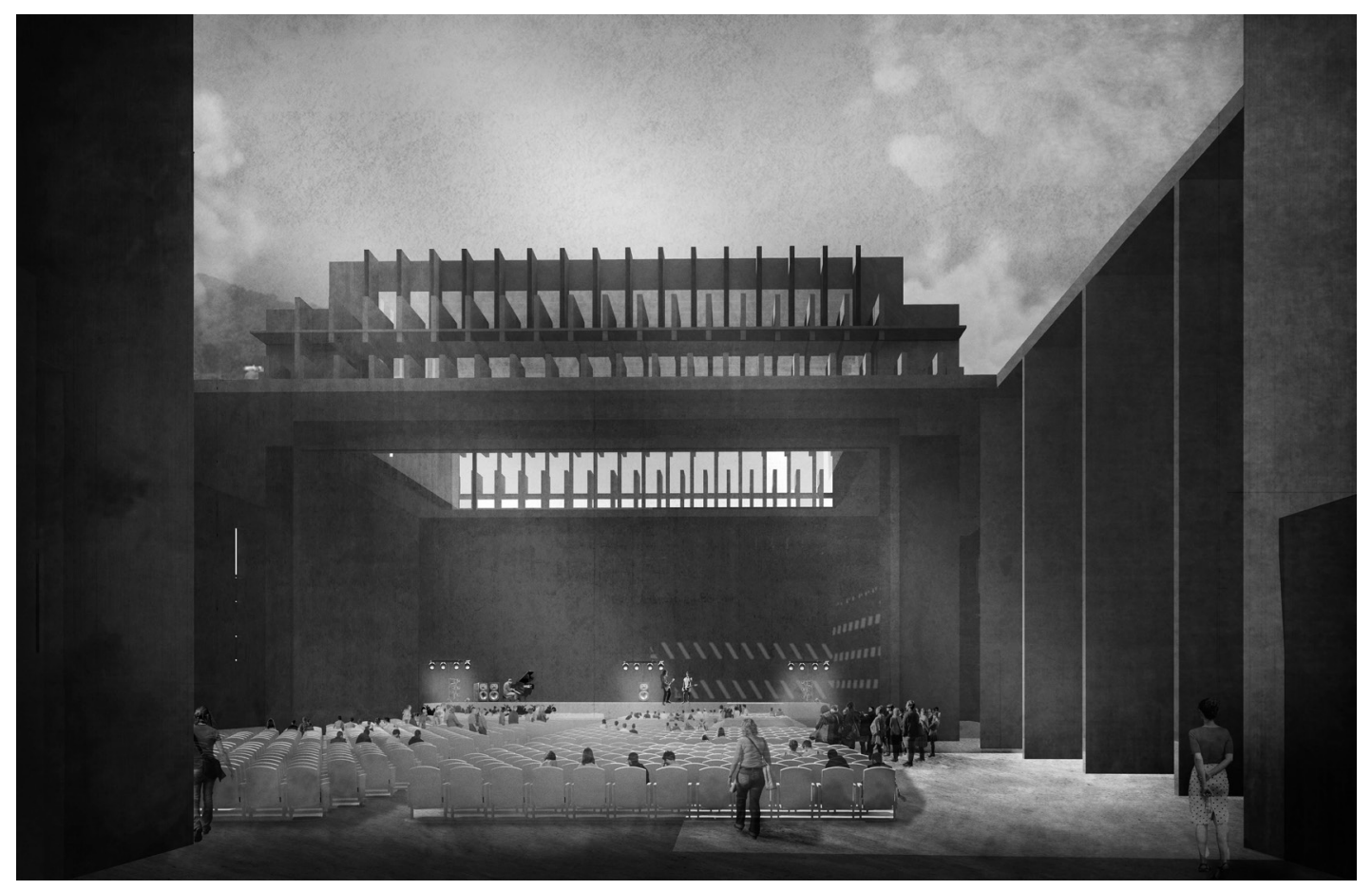

\title{
El diablo está en los detalles
}

\section{Francisco González de Canales}

Recibido 2019.07.16 ::: Aceptado 2019.07.20 DOI: 10.5821/palimpsesto.20.8757

Persona de contacto: francisco@canales-lombardero.com. ORCID: http://orcid.org/0000-0003-0412-7108.

Departamento de Composición Arquitectónica de la ETSA, Universidad de Sevilla (US)

era ni mi tercera semana en Barcelona uando Carlos pidió un corte por fachada a escala 1:10 de la idea de proyecto. Aquello fue una sorpresa. No sólo en tanto al cambio del orden habitual en el desarrollo del proyecto, sino porque viniendo de un contexto en el que el enemigo era el manierismo ya presente desde los 70 , el comenzar el proyecto por el detalle me parecía altamente cospechoso. No podía entender cómo volver al detalle podría cobrar sentido en un mundo que ya por entonces reconocíamos como de cambios y flujos, de circulación constante ¿Qué resistencia al mismo podría tener 'el detalle'? En este mi último curso de carrera, mi formación hasta entonces en base a diagramas y estrategias me parecía mucho más coherente, y aquello otro se me antojaba como una especie de ensimismamiento en lo excesivamente particular. peor aún, como un enrocarse de los arquitectos sobre peor aún, como un enccarse de los arquitectos sobre que se presentaban convulsos. Pero la insistencia era enorme. Se ponía toda la carga en ello. Carlos repetía como un mantra que lo que más le interesaba de la arquitectura eran 'Ios 3 centímetros', aquellos en los que se encuentran los materiales, y así lo expresaba en las charlas con las que presentaba su trabajo, en las visitas de obra que realizamos a lo largo de aquel año..

En aquellas mis primeras semanas en la cátedra blanca presenté mi corte 1:10 con algo de miedo y muchas dudas sobre lo que de él se esperaba. Tuvo que pasar un tiempo para que me diera cuenta de que aquello no iba en absoluto del 'detalle', sino de establecer una coherencia a un cierto nivel profundo capaz de aunar procesos experiencias y escalas descle su propia evidencia. Una coherencia que, su más alto grado, habla precisamente de la ausencia de detalles - en cuanto a soluciones específicas aquí y allá- o lo que es lo mismo, una lógica tan resiliente que viaja de lo micro a lo macro y viceversa manteniendo su propio sentido y presencia. Empecé a entender que era precisamente esta lógica la que hace que el proyecto - ya sea en base a diagramas, estrategias, tipologías... - no se desarbole y diluya en su circunstancia, sino que pueda establecer un dialogo con las contingencias que tanto ahora como el futuro pudieran depararle y construir así soportes de mediación - urbanos, programáticos, habitacionales... - como una referencia común quizá más estable. En todo ello estaba para mí implícito que el trabajo del arquitecto no era sólo producir dibujos - en consonancia con las derivas gráficas del momento - sino ahondar en la materialización de los mismos para desarrollar un sentido de tangibilidad capaz de generar empatías y afectos más amplios entre la arquitectura y sus habitantes.

En estos 20 años desde de aquel curso, esa necesidad de coherencia a través de las distintas escalas de los procesos ha conducido una buena parte de mi carrera divulgativa, académica y profesional. Así lo he tratado de expresar por ejemplo en mi trabajo como divulgador en general del conocimiento sobre la arquitectura. Está presente en la etapa de dirección de la revista del Colegio de Arquitectos de Sevilla, Neutra, pero sobre todo, en exposiciones más recientes de las que he sido comisario como First Works: Emerging Architecture Experimentation of the 1960s and 1970s - parte de mis actividades como AACP coordinator (Architectural Association Curtatorial Practices/Cultural Products) - o Rafael Moneo: Una reflexión teórica desde la Profesión (La Coruña, Lisboa, Méjico, Hong Kong, Madrid). Más allá de tratar de replicar la experiencia de la arquitectura, o documentar su descripción, estas dos exposiciones ponen su énfasis sobre los procesos que la generan, y en particular, sobre el dibujo del arquitecto como herramienta de pensamiento capaz de crear un puente entre arquitectura, ideación y materialización. Otra búsqueda específica sobre la relación entre sensibilidades emergentes y dibujo es la exposición A Minor Architecture, que se inició recientemente Madrid. Su argumento se basa en cómo los géneros menores han servido para ahondar nuevos caminos menores han servido para ahondar nuevos caminos en muchas disciplinas, y cómo la reclusión en obras menores durante estos maltrechos años para la profesión puede convertirse en una oportunidad que tiene además sus propias herramientas gráficas para definir sus hallazgos. Parte de este discurso estará presente también en el número 277 de Quaderns, (Obsessió Ibèrica), de cuya edición formaré parte.
En este repaso no puede quedar atrás el peso que ha tenido la carrera académica hasta la obtención de mi reciente cátedra, y la búsqueda una internacionalización iniciada en Harvard, pero consolidada sobre todo en la Architectural Association (AA) de Londres. Cuando estudiaba en España, había una arquitectura dominante que se daba por hecho que era la que debía de ser seguida. Enfrentarse a un panorama internacional era también presenciar cómo esas certidumbres se desvanecían ante una miríada de posiciones diversas, cada una de ellas con una lógica propia que las abalaba. El paradigma de esta nueva condición sería abalaba. El paradigma de esta nueva condición se para mí la Architectural Association, escuela que un conjunto de escuelas dentro de una misma escuela. Desde la AA, aquella coherencia que se demandaba desde mi experiencia en la cátedra blanca no era ya sólo una aspiración, sino una necesidad para la supervivencia. Mi paso por la AA ha sido así uno de los más útiles en la subsiguiente construcción de los más uties en las ambicion úción radical de ideologias y metodos que la AA proponía -como salvaguardia de la pluralidad a toda costafundamental para seguir puliendo
posición como arquitecto fuera.

Me gustaría por último dejar unas notas sobre la práctica profesional, en la que me ha acompañado todo este tiempo Nuria Álvarez Lombardero, la cual ha estado compartiendo también tanto en la AA. La profesión es de lejos la carrera más larga, y donde se articulan la mayor parte de las inquietudes que Nuria y yo hemos ido desarrollando. Se trata de una carrera que, comenzada algo tardía, se construye no tanto sobre la épica de los grandes concursos, sino desde el oficio y las escalas menores: algunas casas, un pequeño centro de salud algunas instalaciones... A lo largo de este aprendizaje, la carrera profesional desarrollada ha establecido un fuerte compromiso con la exploración de la forma en arquitectura y su particular resiliencia a la hora de establecer relaciones y articular condiciones - algo que se vuelve aún más potente cuando se dota a ésta de un cierta base constructiva que la sustente-. En estos últimos años esta ráctica está tra sustonte-. En estos últimos años esta práclica está tratando de trasladarse a escalas mayores a través de concursos y encargos de mayor envergadura. Entre ellos se destacan un edificio público en San Salvador (El Salvador), un centro deportivo en Sibiu (Rumania), ambas por concurso, y un edificio híbrido en Nairobi (Kenia). Así por ejemplo, mientras el edificio de San Salvador articula las relaciones con lo público a través de la colocación específica de muros verticales de hormigón, el centro de Sibiu se establece en torno al plano horizontal - suelos y cubiertas - para organizar sus espacios. No hay detalles, o al menos, no los hay es sentido de un continuo reguero no los hay en el sentido de un continuo reguero de soluciones especiales. Se pretende que la lógica del muro, o de la cubierta, invada el resto de las decisiones del proyecto: tal y como aprendí de aquella primera cátedra blanca allá por 1999, o al menos, tal y como fue mi interpretación y maduración de esa experiencia.

FRANCISO GONZÁLEZ DE CANALES es Doctor Arquitecto y Catedrático del Departamento de Composición Arquitectónica de la Universidad de Sevilla (US). 